\title{
Accuracy and reliability of two indirect ambulatory blood pressure recorders: Remler M2000 and Cardiodyne Sphygmolog
}

\author{
D J FITZGERALD, W G O'CALLAGHAN, R McQUAID, K O'MALLEY, E O'BRIEN \\ From The Blood Pressure Clinic, The Charitable Infirmary, fervis Street, Dublin, and The Blood Pressure Measurement \\ Laboratory and Department of Clinical Pharmacology, Royal College of Surgeons in Ireland, St Stephen's Green, \\ Dublin, Eire
}

SUMmary The Remler M2000 and Cardiodyne Sphygmolog are semiautomatic recorders designed to measure ambulatory blood pressure non-invasively. These recorders were assessed for accuracy and reliability in a study designed in three stages. Firstly, the interdevice variability was assessed separately for each type of recorder by comparing the recordings of three devices against each other and against simultaneous recordings by a mercury standard in 12 patients, multiple recordings being made in a random order in each patient. The mercury standard used was the London School of Hygiene (LSH) sphygmomanometer and the Hawksley random zero sphygmomanometer during assessment of the Remler and Sphygmolog, respectively. Though there were no differences between the three Remler recorders tested, one Sphygmolog recorder gave higher recordings than the two other Sphygmolog recorders tested because of a zero drift of 3 to $4 \mathrm{mmHg}$ in the pressure transducer. Remler recordings were higher than simultaneous LSH sphygmomanometer recordings for both systolic and diastolic pressures. In the second part of the study, the Remler was compared with the Hawksley using simultaneous recordings in the same arm in 58 patients. No difference was found between Hawksley and Remler recordings. The discrepancy between this and the Remler-LSH comparison resulted from a tendency for the LSH sphygmomanometer to underestimate blood pressure. Similarly, the Sphygmolog recordings were compared with simultaneous Hawksley recordings in 100 patients. No significant difference was found between paired systolic pressure recordings though Sphygmolog recordings underestimated diastolic blood pressure. In the third part of the study, the reliability of the Remler was assessed from 69 attempted day recordings. Five Remler day recordings failed, a major cause of lost recordings being a defect in the microphone lead. The reliability of the Sphygmolog was compared with the Remler by attempting day recordings with each device in 13 patients. The reliability of the Sphygmolog was significantly poorer, only five of 13 Sphygmolog day recordings being decodable because of dislodgement of the recording dise during ambulation.

Single clinic recordings may not reflect the blood pressure behaviour of many patients. ${ }^{1-3}$ Therefore, methods of assessing blood pressure behaviour outside the clinic have been developed and include home recording by the patient ${ }^{45}$ or a relative, ${ }^{6}$ and intraarterial ${ }^{1}$ and indirect ambulatory recording. ${ }^{78}$

Intra-arterial recording is an invasive procedure which is not without risk. ${ }^{9}$ Home recording may be inaccurate because of patient bias. ${ }^{10}$ Indirect ambulatory blood pressure recording should be free of these disadvantages but there have not been many studies on the accuracy of the recorders that are now available.

In this paper we present our findings on the accuracy and reliability of two ambulatory blood pressure recorders, the Remler M2000 and Cardiodyne Sphygmolog.

\section{Methods and results}

The Remler M2000 is a portable blood pressure recorder consisting of a cuff and microphone connected to a pressure transducer and microcassette 


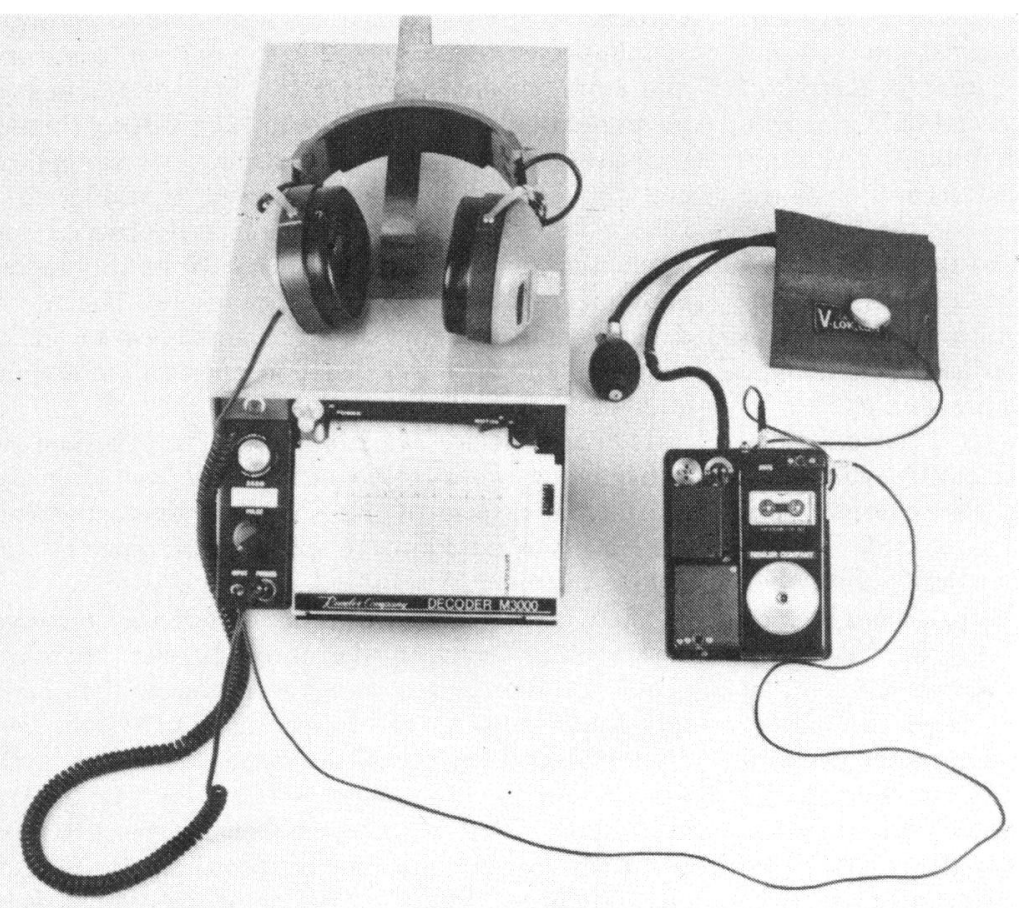

Fig. 1 The Remler M2000 (right) and decoder (left) with example of pressure recording on the strip chart.

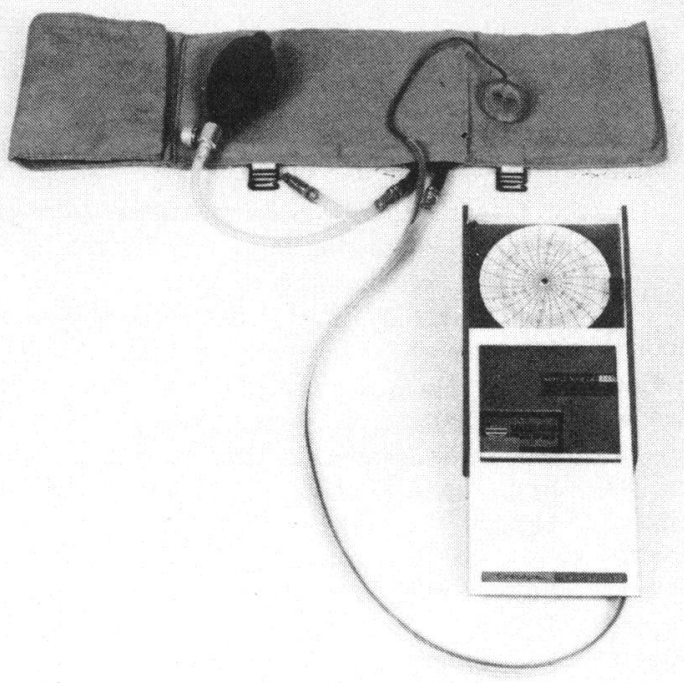

Fig. 2 The Cardiodyne Sphygmolog. 
recorder worn on the patient's waist (Fig. 1). The cuff is inflated by the patient at prescribed intervals and deflates automatically. During deflation the Korotkoff sounds and cuff pressure are recorded on a magnetic tape. The tape is later analysed through a separate decoder which gives a strip chart recording of the sounds superimposed on a tracing of cuff pressure (Fig. 1). The pressures corresponding to the first and last sounds are recorded as the systolic and diastolic endpoints, respectively. As weaker sounds may not deflect the pen in the decoder an observer listens to the tape during decoding and marks on the pressure tracing the position of the first and last sounds. Pen deflections caused by artefacts can be excluded at the same time.

The Cardiodyne Sphygmolog also consists of a sphygmomanometer cuff which is inflated by the patient and which deflates automatically through a needle valve (Fig. 2). The cuff pressure is monitored by a pressure transducer which drives a pen suspended over a paper disc. The Korotkoff sounds are detected by a microphone placed beneath the lower cuff margin and are recorded on to the paper disc by the pen as it moves across the disc. As the disc is calibrated for pressure, the first and last pen marks are recorded as the systolic and diastolic point, respectively. The paper disc is driven by a clockwork mechanism and revolves once in 24 hours. In this way, a real-time recording of daily blood pressures is made. Furthermore, the blood pressure recordings are read directly from the disc, so that a separate decoder or analyser is not required.

For each instrument three devices were tested to detect interdevice variability, a source of possible error in automated devices ${ }^{11}$ which may bias the overall assessment of their accuracy. The accuracy of one of each type of recorder was then tested against a mercury standard. As the decision end-points for systolic and diastolic pressures are observer dependent, interobserver variability in the decoding of pressure recordings was also assessed. The results were analysed by Student's t test for paired data and by linear regression analysis. In all cases phase $\mathrm{V}$ was used as the diastolic end-point.

\section{ACCURACY STUDIES}

\section{(1) Interdevice variability}

The Remler was compared with the London School of Hygiene (LSH) sphygmomanometer ${ }^{12}$ in 12 patients as part of an interdevice variability study of three Remler recorders. Paired LSH sphygmomanometer and Remler recordings were made in the same arm by connecting both devices to a single cuff through a Y connector (Fig. 3a). The stethoscope head and microphone were applied to the same brachial artery without difficulty. Simultaneously a second observer recorded paired Remler-LSH sphygmomanometer recordings in the opposite arm by the same technique. As the two cuffs were interconnected we were able to compare simultaneous Remler recordings in opposite arms and also simultaneous Remler and LSH sphygmomanometer recordings in the same arm. The order of Remler recorders, the arm to which the recorders were applied, and the observers was randomised according to a Graeco-Latin square design. In this way observer and sequential bias, or bias resulting from differences between arms would not influence results. The rate of deflation of the system was set at $3 \mathrm{mmHg}$ per second as we observed that lower deflation rates caused attenuation of the Korotkoff sounds.

The interdevice variability of the Cardiodyne Sphygmolog was assessed in the same way (Fig. 3a) except that instead of the LSH sphygmomanometer the Hawksley random-zero sphygmomanometer ${ }^{13}$ was used as the mercury standard.

There was no significant difference between observers or between the three Remler recorders (Table 1). Remler recordings were higher than LSH sphygmomanometer recordings for both systolic and diastolic blood pressures, the mean differences being $4.8 \mathrm{mmHg}(\mathrm{p}<0.05)$ and $4.7 \mathrm{mmHg}(\mathrm{p}<0.005)$, respectively. This was true whether the mean Remler and LSH sphygmomanometer recordings for each of the 12 patients (Fig. 4) or individual recordings were compared. Furthermore, the mean differences between paired Remler and LSH sphygmomanometer recordings were negatively correlated with heart rate for diastolic $(r,-0.69 n=12, p<0.02)$ but not systolic blood pressures.

Table 1 Comparison of three Remler recorders

\begin{tabular}{lll}
\hline & Systolic $(\mathrm{mmHg})$ & Diastolic $(\mathrm{mmHg})$ \\
\hline Remler 1 & $161 \cdot 6 \pm 4 \cdot 5$ & $94 \cdot 7 \pm 1 \cdot 8$ \\
Remler 2 & $163 \cdot 4 \pm 4 \cdot 4$ & $93 \cdot 7 \pm 2 \cdot 1$ \\
Remler 3 & $161 \pm 4.3$ & $93.4 \pm 1.6$ \\
\hline
\end{tabular}

Values are mean \pm SEM.

Overall, there was no significant difference between paired Sphygmolog and Hawksley recordings in the 12 patients whether the mean data for each patient or individual recordings were compared. One Sphygmolog recorder $\left(S_{1}\right)$, however, significantly overestimated paired Hawksley systolic recordings (Table 2) and comparison of individual paired Sphygmolog recordings in opposite arms showed that $S_{1}$ recordings were higher than $S_{2}$ and $S_{3}$ recordings, the mean difference being $4.3 \mathrm{mmHg}(\mathrm{p}<0.01)$ for systolic and $2.4 \mathrm{mmHg}$ $(p<0.06)$ for diastolic recordings. $S_{2}$ and $S_{3}$ Sphygmolog recordings tended to underestimate Hawksley diastolic pressure recordings (by $2.8 \mathrm{mmHg}$ on average) while $S_{1}$ recordings showed a mean excess of $0.7 \mathrm{mmHg}$ over the Hawksley. 
Table 2 Comparison of paired Hawksley and Sphygmolog recordings for three Sphygmolog recorders

\begin{tabular}{|c|c|c|c|c|c|c|}
\hline & \multicolumn{3}{|c|}{ Systolic $(\mathrm{mmHg})$} & \multicolumn{3}{|c|}{ Diastolic $(m m H g)$} \\
\hline & $\overline{S_{l}}$ & $S_{2}$ & $S_{3}$ & $\overline{s_{l}}$ & $S_{2}$ & $S_{3}$ \\
\hline $\begin{array}{l}\text { No. } \\
\text { Hawksley } \\
\text { Sphygmolog }\end{array}$ & $\begin{array}{l}48 \\
162 \pm 5 \cdot 5 \\
165 \cdot 6 \pm 5 \cdot 8^{\star \star}\end{array}$ & $\begin{array}{l}48 \\
161 \cdot 6 \pm 5 \cdot 3 \\
164 \cdot 8 \pm 5 \cdot 0\end{array}$ & $\begin{array}{l}48 \\
162 \pm 5 \cdot 4 \\
161 \pm 5 \cdot 2\end{array}$ & $\begin{array}{l}48 \\
90 \pm 1.9 \\
90 \cdot 7 \pm 1 \cdot 8\end{array}$ & $\begin{array}{l}48 \\
91 \cdot 3 \pm 1 \cdot 7 \\
88 \cdot 4 \pm 1 \cdot 6^{\star}\end{array}$ & $\begin{array}{l}48 \\
91 \cdot 1 \pm 2 \cdot 0 \\
88 \cdot 4 \pm 1 \cdot 7 \star\end{array}$ \\
\hline
\end{tabular}

Values are mean \pm SEM. ${ }^{\star} p<0.05,{ }^{\star \star} p<0.01$ significantly different from paired Hawksley recordings.

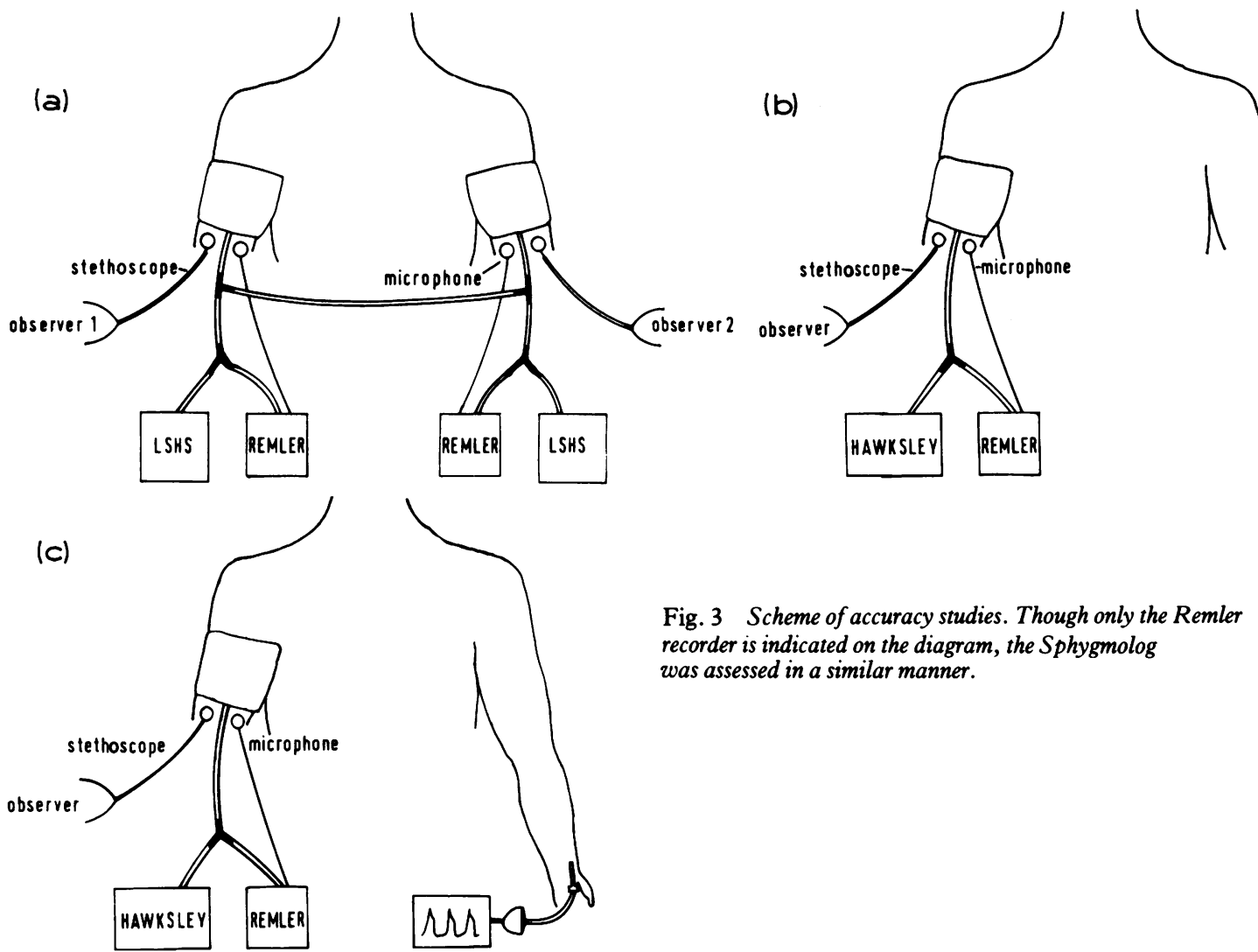

(2) Comparison of simultaneous Hawksley and automatic device recordings

The Remler was compared with the Hawksley random zero sphygmomanometer in 35 patients using simultaneous recordings in the same arm (Fig. 3b). One Remler recorder and one observer were used. Two recordings were made in each patient as not all Remler recordings would be decodable. There was no significant difference between paired Remler and Hawksley recordings using either the mean data for each patient or individual recordings (Table 3).

Similarly, the Cardiodyne Sphygmolog was com-

pared with the Hawksley random zero sphygmomanometer in 100 patients (Fig. 3b), one recording being made in each patient. There was no significant difference between paired systolic recordings (Table 3 ). Sphygmolog recordings, however, slightly underestimated Hawksley diastolic recordings, the mean difference being $2 \mathrm{mmHg}$.

(3) Comparison of Remler and intra-arterial recordings In 23 patients, simultaneous Hawksley and Remler recordings were made in the left arm while intraarterial recordings were recorded from the opposite 
Table 3 Comparison of paired Hawksley and Remler recordings and paired Hawksley and Sphygmolog recordings:

Data for Hawksley-Remler recordings represent mean data ( \pm SEM) for each of 35 patients

\begin{tabular}{|c|c|c|c|c|c|c|}
\hline \multirow[b]{3}{*}{$\begin{array}{l}\text { No. } \\
\text { Mean } \pm \text { SEM } \\
\text { Correlation coefficient }\end{array}$} & \multicolumn{3}{|c|}{ Systolic ( $m m H g$ ) } & \multicolumn{3}{|c|}{ Diastolic ( $m m H g)$} \\
\hline & Hawksley & & Remler & Hawksley & & Remler \\
\hline & $\begin{array}{l}35 \\
162 \cdot 2 \pm 5 \cdot 0\end{array}$ & 0.98 & $\begin{array}{l}35 \\
161 \cdot 8 \pm 5 \cdot 1\end{array}$ & $\begin{array}{l}35 \\
99 \cdot 5 \pm 2 \cdot 8\end{array}$ & 0.97 & $\begin{array}{l}35 \\
99 \cdot 9 \pm 2 \cdot 8\end{array}$ \\
\hline & Hawksley & & Sphygmolog & Hawksley & & Sphygmolog \\
\hline $\begin{array}{l}\text { No. } \\
\text { Mean } \pm \text { SEM } \\
\text { Correlation coefficient }\end{array}$ & $\begin{array}{l}100 \\
160 \cdot 1 \pm 3 \cdot 0\end{array}$ & 0.98 & $\begin{array}{l}100 \\
159 \cdot 0 \pm 2 \cdot 9\end{array}$ & $\begin{array}{l}100 \\
93 \cdot 8 \pm 1 \cdot 7\end{array}$ & 0.97 & $\begin{array}{l}100 \\
92 \pm 1 \cdot 8^{\star}\end{array}$ \\
\hline
\end{tabular}

${ }^{\star} \mathrm{p}<0.001$, significantly different from paired Hawksley recordings.

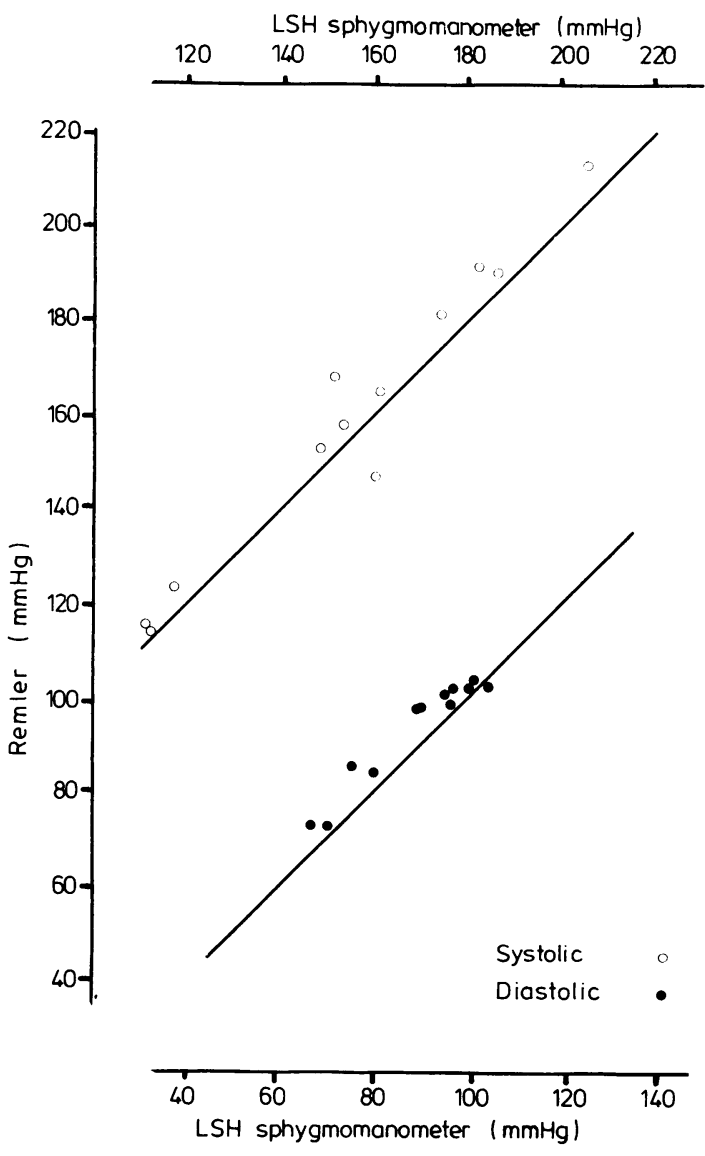

Fig. 4 Comparison of mean LSH sphygmomanometer and Remler paired recordings in each of 12 patients. Lines of identity are given.

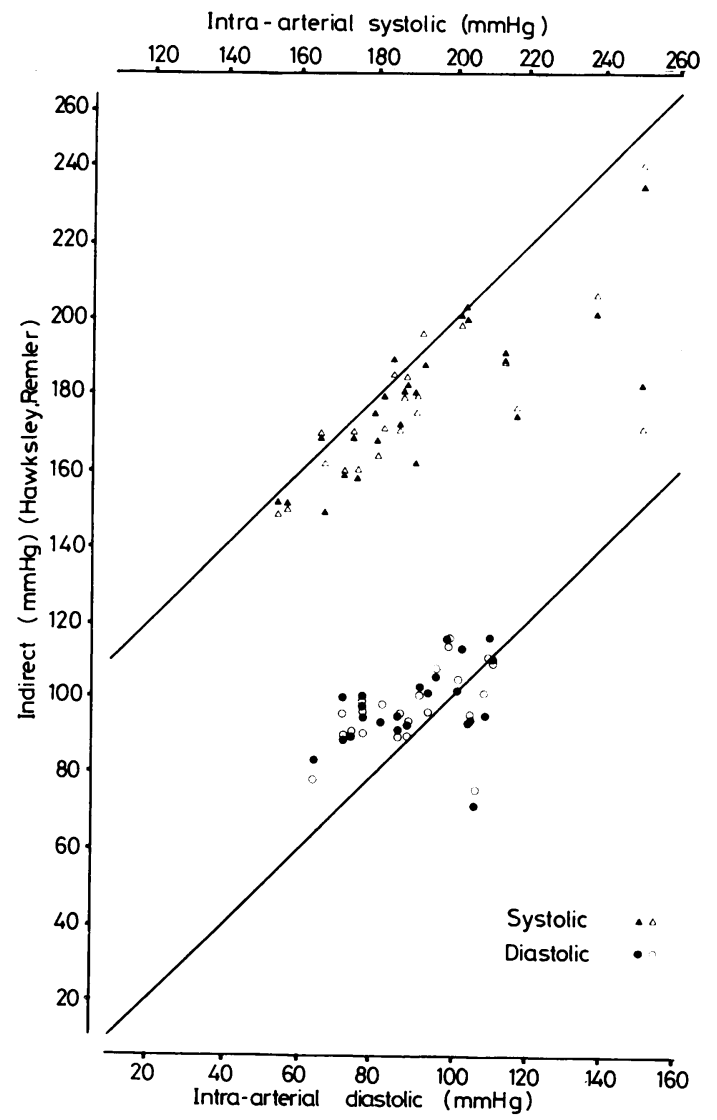

Fig. 5 Comparison of Remler and Hawksley recordings with intra-atrial recordings. Lines of identity are given. Remler recordings are indicated by the closed symbols and Hawksley recordings by the open symbols. 
radial artery through a Bell and Howell pressure transducer on to light sensitive paper (Fig. 3c). Three recordings were made in each patient as not all Remler recordings would be decodable.

The relation between Remler and intra-arterial recordings was the same as between Hawksley and intra-arterial recordings for both systolic and diastolic blood pressures (Fig. 5, Table 4). Again, there was no significant difference between Hawksley and Remler recordings.

\section{RELIABILITY STUDY}

The reliability of the Remler in recording ambulatory blood pressure was assessed by determining the number of decodable recordings from 69 attempted Remler ambulatory day recordings. Of these, five failed completely, in three cases because the microphone lead broke and in two because of a defect in the "off" pressure switch which failed despite normal deflation. In the remaining 64 tapes, 1129 pressure recordings were attampted and $104(9 \cdot 2 \%)$ of these were undecodable. In $35(3 \cdot 1 \%)$ this was because of the failure of the microphone to detect any sounds and in the remainder because of either incorrect setting of the on-off pressure switches or patient movement.

In 13 hypertensive patients the reliability of Sphygmolog ambulatory recordings was compared with that of Remler ambulatory recordings. Recordings with each device were carried out in each patient on separate days during normal daily activities. The order of machines was randomised to prevent a training effect and treatment between the two days was not altered.

In only five of 13 Sphygmolog day recordings could a reasonable attempt be made at analyses compared with 12 of 13 Remler day recordings $\left(X^{2} 5.42\right.$ after Yates correction, $\mathrm{p}<0.02)$. In the remaining eight, there were no decodable recordings. In six cases this was the due to dislodgement of the paper disc from the motor spindle and in two a large number of artefacts made decoding impossible. The one Remler failure resulted from an excessive cuff deflation rate.

INTEROBSERVER VARIABILITY IN DECODING Interobserver variability in decoding was assessed by comparing the decoded results of two observers for 120
Remler and 88 Sphygmolog blood pressure recordings made in the laboratory.

There was no significant difference between the two observers in decoding Remler recordings, but $10 \%$ of all decoded recordings differed by more than \pm 5 $\mathrm{mmHg}$, the mean difference being $0 \cdot 7 \pm 4 \cdot 2 \mathrm{mmHg}$ for systolic and $0.6 \pm 5.4 \mathrm{mmHg}$ for diastolic blood pressure recordings. The paired decoded recordings were highly correlated for systolic $(\mathrm{r}, 0.99, \mathrm{p}<0.001)$ and diastolic $(r, 0.93, p<0.001)$ recordings. Similarly, there was no significant difference between observers for decoding Sphygmolog systolic recordings though there was a small difference for diastolic recordings, the mean being $1 \mathrm{mmHg}(\mathrm{p}<0.01)$. The paired decoded recordings were again highly correlated for both systolic ( $\mathrm{r}, 0.98, \mathrm{p}<0.001$ ) and diastolic (, 0.99 , $\mathrm{p}<0.001)$ pressures. Of the 88 paired decoded recordings, $9 \cdot 2 \%$ of systolic and $5 \%$ of diastolic recordings differed by more than $5 \mathrm{mmHg}$.

\section{Discussion}

Accuracy studies of automated blood pressure recorders are beset with problems, including the variation between repeated blood pressure measurements, interdevice variability, ${ }^{11}$ observer error,${ }^{14}$ and the type of standards against which they should be tested. 1516 . Where it is possible, as for these two machines, to apply both the standard and automatic recorders to the same brachial artery, comparison of simultaneous recordings in the same arm is the ideal method of assessment. ${ }^{17}$ This removes the effect of blood pressure variability, which may otherwise be ascribed to the method of blood pressure recording under test. Furthermore, by comparing the recordings of a number of test instruments made repeatedly in a small group of patients, interdevice differences are easily detected which would otherwise require recordings from large numbers of subjects. Simultaneous mercury sphygmomanometer recordings can be used as a standard against which these differences are confirmed, excluding blood pressure variability as a possible cause.

The accuracy of the Remler M2000 has been assessed previously with varying results. ${ }^{18-22}$ In two studies in which the standard used for comparison was the LSH sphygmomanometer, the Remler was found to over-

Table 4 Comparison of mean Remler, Hawksley, and intra-arterial recordings in each of 23 patients

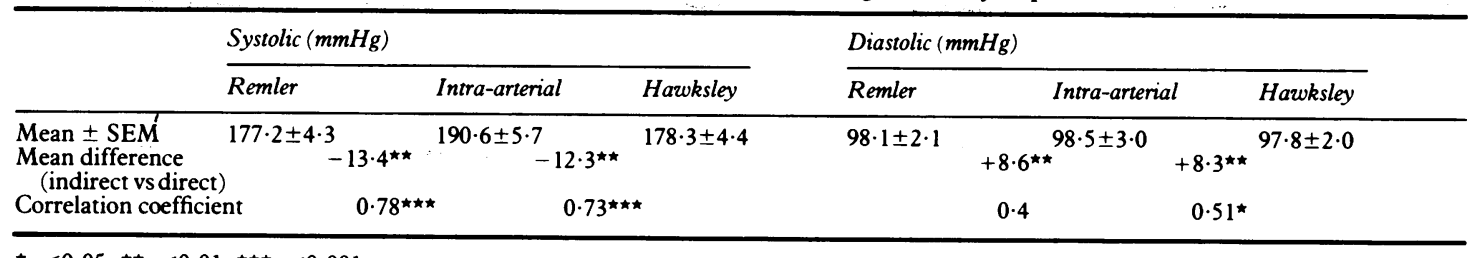

${ }^{\star} \mathrm{p}<0.05,{ }^{\star \star} \mathrm{p}<0.01,{ }^{\star \star \star} \mathrm{p}<0.001$. 
estimate systolic and diastolic blood pressures. 1820 In contrast, when compared with the Hawksley ${ }^{22}$ or a standard mercury sphygmomanometer, ${ }^{19}$ the Remler showed no mean bias. In this study the Remler recordings were higher than simultaneous LSH sphygmomanometer recordings, whereas there was no difference between Remler and Hawksley recordings. This is consistent with our previous finding that the LSH sphygmomanometer underestimates blood pressure partly because of incorrect calibration but also because of an interpretative difference between the LSH sphygmomanometer and other methods of blood pressure measurement. ${ }^{23}$ The interpretative difference results in an error during blood pressure recording which is heart rate dependent ${ }^{23}$ and is confirmed in this study by the negative correlation between the mean Remler-LSH sphygmomanometer differences for diastolic blood pressure and heart rate.

Comparison of Remler and intra-arterial recordings has shown a systematic error of $+3 /+2 \mathrm{mmHg}{ }^{21} \mathrm{The}$ relation of indirect to intra-arterial measurement, however, is highly variable. ${ }^{24-26}$ Therefore, comparison of Remler and intra-arterial recordings should be assessed by simultaneous comparison of Remler and mercury sphygmomanometer recordings with intra-arterial recordings. In this study the mean bias and relation between direct and indirect recordings was the same for Remler and Hawksley recordings.

A possible source of variability and bias in Remler recordings is the interobserver difference in the decoding process. Though no significant difference was found between observers, decoded results could differ by more than $5 \mathrm{mmHg}$ in $10 \%$ of recordings. This may partly explain the scatter of Remler recordings when compared with standard mercury sphygmomanometer recordings. ${ }^{23}$ This interobserver variability, however, is no greater than for standard sphygmomanometer recordings. 15

The reliability of Remler ambulatory recordings is reduced to a large extent by defects in the microphone lead. This also reduces the availability of the recorder as broken microphones must be returned to the manufacturer for repair, and recorders may lie idle for some time.

The Cardiodyne Sphygmolog is the simplest and most inexpensive complete ambulatory blood pressure system available. Though on the market, it has not been previously evaluated. Accuracy studies showed that the Sphygmolog tended to underestimate diastolic pressure when compared with the Hawksley randomzero sphygmomanometer. This difference, however, was small, and overall this device was reasonably accurate. Interdevice variability studies showed that one recorder gave higher recordings than the two other devices tested. This was the result of a zero drift of 3 to $4 \mathrm{mmHg}$ in the pressure transducer.
Reliability of the Sphygmolog recorder was low. This was not the result of poor technique by the patients as recordings with the Remler M2000 were successful. The main defect, which appears easily correctable, is that the recording discs are displaced from the motor spindle when the machine is in the upright position during ambulatory recording. Even if this were corrected, however, there were a large number of artefacts in two of the remaining day recordings. This may be because of oversensitivity of the recording system, which would explain the tendency to underestimate diastolic pressure, and the absence of any system in the recorder for artefact suppression. Artefactual recording is a major problem during automated blood pressure recording, ${ }^{27}$ the commonest cause being movement of the patient's arm. This may be overcome by either using appropriate band filters, ${ }^{28} 29$ so that only sounds with the frequency characteristics of Korotkoff sounds ${ }^{30}$ are recorded, or by recording sounds occurring within a short period after the QRS complex of the electrocardiogram. ${ }^{831-33}$ With some systems ${ }^{734}$ the observer analyses the recorded data and artefacts are rejected on the basis of the occurrence of sounds in an expected position or sequence, or by rejecting recordings altogether as undecodable. In contrast, the permanent record of the pressure measurements made by the Sphygmolog gives no indication whether pen marks are the result of Korotkoff sounds, arm movement, or extraneous sounds.

In conclusion, the Remler M2000 semiautomatic portable recorder is accurate in the measurement of blood pressure. Differences in the findings of previous studies can be explained by the different standards used for comparison. The reliability of the Remler M2000 could be improved by strengthening the microphone lead attachment to the microcassette recorder. The Sphygmolog is a reasonably accurate though unreliable method of recording ambulatory blood pressure. Reliability is poor mainly because of a defect in the method used to retain the paper discs on the revolving spindle of the motor. The Cardiodyne Sphygmolog, as presently designed, cannot be recommended for ambulatory blood pressure monitoring.

We acknowledge the support of the Royal College of $N$ Surgeons in Ireland and Ciba Laboratories, and Cardiodyne General, Inc., 455 Los Gatos Blvd., Los Gatos, California, USA, for supplying us with three Sphygmologs for testing.

\section{References}

1 Floras JS, Hassan MO, Sever PS, Jones JV, Osikowska B, Sleight $P$. Cuff and ambulatory blood pressure in subjects 
with essential hypertension. Lancet 1981; ii: 107-9.

2 Sokolow M, Werdegar D, Kain HK, Hinman AT. Relationship between level of blood pressure measured casually and by portable recorders and severity of complications in essential hypertension. Circulation 1966; 34: 279-98.

3 Julius S, Ellis CN, Pascual AV, et al. Home blood pressure determination: value in borderline (labile) hypertension. FAMA 1974; 229: 663-6.

4 Ayman D, Goldshine AD. Blood pressure determinations by patients with essential hypertension. 1 . The difference between clinic and home readings before treatment. Am $\mathcal{F}$ Med Sci 1940; 200: 465-74.

5 Laughlin K, Fisher L, Sherrard DJ. Blood pressure reductions during self-recording of home blood pressure. Am Heart f 1979; 98: 629-34.

6 Laher MS, O'Boyle CP, Quinn C, O'Malley K, O'Brien ET. Home measurement of blood pressure: training of relatives. Ir Med f 1981; 74: 113-4.

7 Hinman AT, Engel BT, Bickford AF. Portable blood pressure recorder. Accuracy and preliminary use in evaluating intra-daily variations in pressure. Am Heart $\mathcal{F} 1962$; 63: 663-8.

8 Horan MJ, Padget NE, Kennedy HL. Ambulatory blood pressure monituring: recent advances and clinical applications. Am Heart f 1981; 101: 843-8.

9 Littler WA. Median nerve palsy-a complication of brachial artery canulation. Postgrad Med F 1976; 52, suppl 7: 110-1.

10 Raftery EB. The methodology of blood pressure recording. Br f Clin Pharmacol 1978; 6: 193-201.

11 Labarthe DR, Hawkins CM, Remington RD. Evaluation of performance of selected devices for measuring blood pressure. Am F Cardiol 1973; 32: 546-53.

12 Rose GA, Holland WW, Crowley EA. A spkyyinomanometer for epidemiologists. Lancet $1964 ; \mathrm{i} ; 2^{\circ}-300$.

13 Wright BM, Dore CF. A randon-eru sphygmomanometer. Lancet 1970; i: 337-8.

14 Rose G. Standardisation of observers in blood pressure measurement. Lancet 1965; i: 673-4.

15 Association for the Advancement of Medical Instrumentation. Standard for electronic or automated sphygmomanoweters (proposed) AAMI ESP-D, February revision. 1982. (Available on request from 1901 North Fort Myer Drive, Arlington VA 22209.)

16 Fitzgerald DJ, O'Malley K, O'Brien ET. Assessing automated blood pressure recorders (letter). Lancet 1981; ii: 993.

17 DHEW. Automated blood pressure measuring devices for mass screening. Publication No. (NIH) 76-929. 1979.

18 Beevers DG, Bloxham CA, Backhouse CI, Lim CC, Watson RDS. The Remler M2000 semi-automatic blood pressure recorder (letter). Br Heart $\mathcal{F}$ 1979; 42 : 366.
19 Cowan R, Sokolow M, Perloff D. The Remler ambulatory blood pressure recording system. Accuracy and reliability (letter). Br Heart f 1980; 43: 715-6.

20 Fong PL, Wilson LL, Richardson EJ, O'Halloran M. Remler recorder (letter). Med f A ust 1979; ii: 312.

21 Gould BA, Hornung R, Kieso H, Cashman PMM, Altman DG, Raftery EB. A validation of the Remler M2000 and Avionic 1978 pressurometer (abstract). Clin Sci 1981; 61: 47p.

22 Scott AK, Petrie JC. Assessment of the Remler blood pressure recording system (abstract). Brf Clin Pharmacol 1982; 13: 289-90.

23 Fitzgerald DJ, O'Malley K, O'Brien ET. Inaccuracy of the London School of Hygiene sphygmomanometer. $\mathrm{Br}$ Med F 1982; 284: 18-9.

24 Breit SN, O'Rourke MF. Comparison of direct and indirect arterial pressure measurements in hospitalised patients. Aust NZF Med 1974; 4: 485-91.

25 Holland WW, Humerfelt S. Measurement of bloodpressure: comparison of intra-arterial and cuff values. $\mathrm{Br}$ Med f 1964; ii: 1241-3.

26 Raftery EB, Ward AP. The indirect method of recording blood pressure. Cardiovasc Res 1968; 2: 210-8.

27 Kantrowitz P. A review of non-invasive blood pressure measurement using a cuff, with particular respect to motion artefact. Biomedical Engineering 1973; 8: 480-1.

28 Lewis FJ, Walker DC, Lee B, Quinn ML. Indirect bloodpressure measurement as part of a computer-controlled patient-monitoring system. Biomed Comput Technol 1976; 1: $39-44$.

29 Katona Z, Bolvary G. Automatic indirect sphygmomanometry. Biomed Eng 1975; 10: 405-10.

30 McCutcheon EP, Rushmer RF. Korotkoff sounds. An experimental critique. Circ Res 1967; 20: 149-61.

31 Lagerwerff JM, Luce RS. Artifact suppression in indirect blood pressure measurements. Aerosp Med 1970; 41: $1157-61$.

32 Steen SN, Grissman FL. A new system for the indirect measurement of systolic and diastolic blood pressures. Anesth Analg (Cleve) 1962; 41: 391-6.

33 Geddes LA, Hoff HE, Vallbona C, Harrison G, Spencer WA, Canzoneri J. Numerical indication of indirect systolic and diastolic blood pressures and respiratory rate. Anesthesiology 1962; 25: 861-6.

34 Wolthius R, McAfoose D, Hull D, Fischer J. Portable blood pressure measurements using the Korotkov sound technique-a study of measurement accuracy. Biomed $S c i$ Instrum 1979; 15: 101-4.

Requests for reprints to Dr E O'Brien, The Blood Pressure Clinic, The Charitable Infirmary, Jervis Street, Dublin 1. 